\title{
Molecular characterization of Bipolaris sorokiniana populations from winter cereals
}

ANJU BALA* AND YOGESH VIKAL ${ }^{1}$

Regional Research Station (P.A.U.), ABOHAR (PUNJAB) INDIA

${ }^{1}$ School of Agricultural Biotechnology, Punjab Agricultural University, LUDHIANA (PUNJAB) INDIA

\section{ARITCLE INFO}

Received : 10.05 .2012

Revised : 26.08.2015

Accepted : 11.09 .2015

\section{KEY WORDS :}

Bipolaris sorokiniana, RAPD markers, Molecular characterization, Cereals

*Corresponding author:

Email: anjuchani@yahoo.co.in

\begin{abstract}
Isolates of B. sorokiniana were obtained from infected leaf samples of bread wheat, durum wheat, barley, triticale and rye leaves collected randomly from Gurdaspur, Ludhiana and Ferozepur areas of Punjab. Based on qualitative colony parameters, 30 isolates were selected for further studies. Molecular characterization of the isolates was done using 30 RAPD primers and Polymorphic Information Content values for these ranged from 0.51 to 0.98 with an average of 0.72 . A total of 197 alleles were amplified out of which 184 were polymorphic and 13 were monomorphic. The number of alleles amplified varied from 3-13 and size of amplified fragments varied from $3.5 \mathrm{~Kb}$ to $200 \mathrm{bp}$. The similarity index values ranged from 0.48 to 0.78 indicating wide range of genetic diversity among isolates. On cluster analysis of the molecular data, the isolates were grouped into two major clusters at 50 per cent level of similarity, whereas at 60 per cent similarity coefficient, the isolates were grouped into 10 clusters. Five complete clusters were formed by 25 isolates whereas 5 isolates formed independent lineages. RAPD profiles, however, did not correlate polymorphism with the geographic source or host source of the isolates.
\end{abstract}

How to view point the article : Bala, Anju and Vikal, Yogesh (2015). Molecular characterization of Bipolaris sorokiniana populations from winter cereals. Internat. J. Plant Protec., 8(2) : 331337. 